\title{
¿Arte o artesanía? Imaginarios occidentales sobre la autenticidad del arte en culturas indígenas
}

\section{Art or Crafts? Western Imageries on the Authenticity of Art from Indigenous Cultures}

\author{
Alessandra Caputo Jaffé \\ Universidad Adolfo lbáñez \\ alessandra.caputo@uai.cl
}

\section{Resumen}

Este artículo reflexiona acerca de las categorías estéticas entre las nociones de arte y artesanía en objetos procedentes de culturas no-occidentales. Usando como ejemplo el caso venezolano, se compararán el "arte" prehispánico con las "artesanías" procedentes de sociedades amerindias en las que se entretejen las tradiciones ancestrales y las formas de vida occidentalizadas. La diferenciación en el juicio entre una y otra forma estética se debe a que al arte de sociedades indígenas alejadas del mundo occidentalizado se le atribuye una autenticidad artística, mientras que la artesanía pierde su autenticidad cuando es producto de una sociedad que está en proceso de mestizaje con Occidente. Se intentará, por tanto, proponer alternativas interpretativas tomando en cuenta los significados que estos objetos tienen desde la perspectiva de las sociedades indígenas actuales.

Palabras clave: arte y artesanía, percepción estética, mundo amerindio, arte no-occidental.

\begin{abstract}
This article explores the aesthetic categories between the concepts of Arts and Crafts, in objects that pertain to non-Western cultures. Using the Venezuelan case as an example, the pre-Hispanic "art" will be compared with the "handicrafts" from Amerindian societies in which ancestral traditions and westernized life forms are interwoven. The differentiation in the judgement between one aesthetic and the other is due to the fact that the art of indigenous societies far from the westernized world is attributed an artistic authenticity, while the craftsmanship loses its authenticity when it is the product of a society that is in the process of miscegenation with the West. An attempt will therefore be made to propose interpretative alternatives taking into account the meanings that these objects have from the perspective of current indigenous societies.
\end{abstract}

Keywords: art and crafts, aesthetic perception, Amerindian world, non-Western art. 
Cuando las estatuas han muerto, ellas entran en el arte. Esta botánica de la muerte es lo que nosotros llamamos cultura.

Les Statues meurent aussi (1953)

Alain Resnais y Chris Marker

Que los objetos sagrados y rituales de culturas ajenas a la tradición europea sean apropiados como arte (en su acepción inscrita en las "altas" esferas de la cultura) no es un concepto lejano a la estética occidental. El proceso de inclusión de las prácticas visuales no-occidentales en el ámbito del arte, tal como es entendido desde la tradición europea, ha pasado por distintas fases y se ha consolidado por diversas razones, no siempre motivadas por un apego desinteresado hacia estas culturas. Uno de los ejemplos paradigmáticos en torno a este tema ha sido la apropiación del arte de África, Oceanía y Norteamérica por los artistas de Vanguardias durante la primera mitad del siglo xx; hecho que daría paso al Primitivismo (véase por ejemplo Primitivism in Modern Art de Robert Goldwater). A partir del interés de artistas como Gauguin, Vlaminck, Picasso, Matisse y Derain (entre tantos otros) hacia las obras de arte de las culturas que entonces eran llamadas "primitivas", comenzaría a la par una valoración estética de estos objetos cuyos lenguajes visuales aludían directamente a la voluntad artística - abstracta, simbólica - de los vanguardistas.

Nacería entonces una particular relación entre el arte occidental y el arte nooccidental, que respondía a una comunión entre la estética europea con las prácticas rituales y representaciones míticas de otras culturas; hecho que a la vez se encontraba íntimamente ligado a una relación colonialista y a una forma de apropiación de las sociedades sometidas al mundo "moderno". De esta manera, los objetos recolectados durante expediciones en países colonizados que se hallaban hasta entonces en gabinetes de curiosidades, museos de ciencia o museos etnográficos, comenzarían a incursionar, tímidamente, por los museos de arte — paradigmático ejemplo sería la exposición de William Rubin del MoMA de 1984, Primitivism in $20^{\text {th }}$ Century Art, donde obras de célebres artistas de las Vanguardias se encontraban acompañadas de objetos del "mundo primitivo" que les sirvieron de modelo o inspiración-.

Las colecciones de objetos "primitivos" procedentes de culturas arcanas — tanto del pasado remoto como algunas culturas que aún se encontraban libres de cualquier contacto con el mundo "modernizado" - se teñirían así de un particular "aura" estético que los ubicaba en un espacio atemporal, o más bien, en el illus tempus. De la misma manera, a los objetos del pasado precolombino les fueron otorgados automáticamente su autenticidad artística ya que nos remiten a culturas desconocidas, lo que les confiere un carácter estético particular. También pueden incluirse en este ámbito los objetos rituales recolectados por exploradores en época colonial de culturas indígenas con 
las que se tenía poco contacto y que eran vistas entonces como supervivientes de los tiempos "primordiales" de la humanidad o pertenecientes a un "estado de naturaleza".

Un destino distinto han vivido, en cambio, aquellas imágenes y objetos del mundo indígena que, aparte de conformar los iconos de una religiosidad particular, también cumplen otras funcionalidades — práctica, social, política, económica, etc.-; sobre todo cuando sus funciones o usos tienen alguna relación con el mundo occidentalizado. Al encontrarse intrínsecamente relacionadas con lo utilitario, los cánones artísticos occidentales aún tienen dificultades en reconocer objetos cuya funcionalidad se desliga de una noción de autonomía estética (que aún prevalece en muchos ámbitos) o de valores que, en el caso del arte no-occidental, están relacionados a lo sagrado y a lo ritual (lo cual les otorga autenticidad). Pero ha sido aún más difícil darles cabida a aquellas prácticas estéticas procedentes de sociedades indígenas que actualmente se encuentran en relación con el mundo occidental; sociedades "híbridas" —en términos de García Canclini-, que han adoptado ciertas costumbres o formas de vida procedentes del mundo occidentalizado, manteniendo sin embargo parte de sus propias cosmovisiones y tradiciones.

Existen algunos casos en los que el arte de culturas indígenas del presente ha encontrado un lugar en colecciones de arte. No obstante, su lugar común suele ser más bien las colecciones de arte etnográfico, arte folklórico e incluso de ciencias naturales, donde estos objetos son vistos desde una perspectiva distinta, de interés antropológico, científico e histórico, mas no estético. La intención de este artículo es resaltar, por lo tanto, la relevancia de este valor estético en objetos creados por culturas indígenas que coexisten actualmente con la sociedad occidentalizada. Y así, analizaremos no solo los posibles significados que pueden adquirir estos objetos para el espectador de tradición europea, sino también desde la propia perspectiva de las culturas indígenas y sus creadores. Dichos objetos se encuentran íntimamente imbricados tanto con lo utilitario como con lo mítico para las culturas que los originan (si bien adquieren en cada contexto cultural un matiz distinto). Por lo tanto, la experiencia sensible se convierte aquí en una forma de conocimiento y de reactivación o reactualización de su identidad cultural, sus mitos y, por tanto, de su cosmovisión particular. ${ }^{1}$

Este artículo escudriña así las problemáticas en torno a la valoración estética de objetos pertenecientes a la cultura material no-occidental, teniendo en cuenta las concepciones de arte, artesanía y autenticidad. Específicamente, nos centraremos en el estudio de las sociedades amerindias utilizando como ejemplo el caso venezolano a partir de anteriores investigaciones (Caputo Jaffé "Entretejidos"). Nos ocuparemos de la valoración del arte prehispánico frente a las artesanías elaboradas actualmente por diversas sociedades amerindias que viven en contacto con el mundo occidentalizado, y por lo tanto, en un punto intersticial entre sus tradiciones ancestrales y las costumbres y formas de vida que han ido adquiriendo a partir de la relación con el mundo de tradición europea.

1 Véase, desde la perspectiva antropológica, a Hussak van Velthem. 
Particularmente, nos centraremos en comprender los motivos por los que los objetos de sociedades que no han estado en contacto con el mundo occidentalizado - como las culturas precolombinas - han sido catalogados como "arte" mientras que a la mayoría de las prácticas estéticas de culturas que han vivido un proceso de mestizaje a partir del contacto con el mundo occidental se las denomina generalmente como "artesanía” y, con ello, se las reduce por lo general a una valoración estética inferior. Sostenemos que las relaciones que aquí se estudian entre arte y artesanía conforman un campo fértil para comprender los motivos por los que desde las concepciones estéticas se apropian objetos procedentes de culturas no-occidentales.

Para comprender esta distinción en la valoración de los objetos amerindios, es importante tomar en cuenta el cambio producido dentro de los cánones artísticos occidentales a partir del siglo xx, época en la que los conceptos de arte forjados desde el Renacimiento y afianzados teóricamente en la Ilustración comenzaron a desmoronarse. Partimos de la hipótesis que en la valoración estética de objetos procedentes de culturas no-occidentales la atribución de "arte" suele asociarse generalmente a significados relacionados con lo sagrado y la autenticidad - hecho que se valida a partir de la lejanía que pueda tener esta cultura con el mundo occidental-, mientras que el concepto de artesanía suele aplicarse a contextos y significados desacralizados e hibridados con el mundo occidentalizado.

Lelia Delgado ha advertido en dicho sentido cómo la lectura que se le ha dado al arte prehispánico en Latinoamérica se fundamenta en motivos que a veces implican actitudes e intereses contradictorios. En un marco de exotismo, el arte prehispánico presenta una colección de objetos que, como "fetiches", se igualaron de manera un tanto incómoda a las obras de arte. Vistos de este modo, "dichos objetos decían muy poco sobre los hombres que habitaron nuestro territorio" (Delgado). Queda claro, pues, que al intentar catalogar las producciones simbólicas de culturas no-occidentales como artísticas, por lo general se les ha dado a estas una lectura parcializada y eurocéntrica. De acuerdo con lo expuesto por Estela Ocampo en Apolo y la máscara, "suponer que existe en los objetos estéticos no europeos una concepción autónoma de las formas, una teorización acerca de métodos y materiales 'artísticos', es pecar de etnocentrismo" (Apolo 19).

Por lo tanto, retomando las reiteradas críticas que se han realizado sobre el tema (Bourdieu 245-247), si nos apropiamos de estas manifestaciones y las catalogamos como artísticas, debemos ser conscientes de que estas no fueron elaboradas según la concepción de un "arte autónomo". Más bien se trata de prácticas que, si bien contienen un alto valor estético, incluyen dentro de sí varias connotaciones, ya sean religiosas, políticas, sociales, como también utilitarias. Ocampo utilizó en este sentido el término de "prácticas estéticas imbricadas" (Apolo 19) para determinar dicho tipo de manifestaciones sensibles, que se encuentran intrínsecamente conectadas con diversos valores que son a la vez utilitarios y trascendentales. De esta manera, se entiende un arte que se encuentra más en sintonía con los lenguajes contemporáneos 
artísticos, donde cada vez se hace más difícil reconocer una completa "autonomía" artística en términos kantianos.

En dicho sentido, el hecho de haber sido concebidas según concepciones distintas a las del arte de tradición europea, no excluye la posibilidad que desde este criterio estético puedan ser concebidas como arte. En sintonía con la concepción estética afianzada a partir de Baumgarten, las "obras de arte" amerindias - tanto aquellas procedentes de periodo prehispánico como aquellas que encontramos en sociedades indígenas del presente- nos transmiten un conocimiento a través de lo sensible. Sostenemos por ello que estas experiencias sensoriales transmiten una sabiduría que trasciende al individuo y a la cultura que las realiza. Más allá del debate acerca de si se puede catalogar un objeto cultural no-occidental como artístico o no, lo que suele apreciarse en estas "prácticas estéticas imbricadas" es su valor epistemológico.

\section{La estetización del pasado o del mundo indígena apartado de la influencia occidentalizada}

En su ensayo Artifact and Art: African Art in anthropology collections, Arthur Danto expuso la problemática entre qué es y qué no es arte, aplicado al caso de las prácticas estéticas no-occidentales, y llegó a la conclusión de que estos objetos podrían ser considerados artísticos únicamente si se encontraban cargados de conocimiento y de valores sagrados y trascendentales para las sociedades que los habían realizado (32). Estableció, de este modo, una distinción entre el objeto creado con una función puramente utilitaria (artifacts) y el objeto que, a pesar de ser útil, remite a algo más, que contiene un valor simbólico que trasciende su forma y función. Mas puede resultar muy difícil, e incluso arbitrario, atribuirle o dejar de atribuirle significados a los objetos "útiles", sobre todo si no han sido concebidos dentro del propio contexto histórico y/o cultural.

Una crítica a esta necesidad de encontrarle a toda forma estética una autonomía y autenticidad artística ya la documenta Ticio Escobar, explicando hasta qué punto objetos como vasijas han sido vistas desde la tradición occidental moderna como carentes de contenido (35). No obstante, dependiendo de qué cerámica se tratase, a esta le sería atribuida un contenido particular, como ha sucedido con las cerámicas de arte precolombino (figura 1).

No hay que olvidar que incluso antes el nacimiento del museo - en los gabinetes de curiosidades, creados durante las primeras colonias europeas - la mayoría de los objetos coleccionados, que se apreciaban con una mirada sorprendida y fascinada ante lo exótico y lo desconocido, no habían sido creados con una intencionalidad artística, sino que eran elaborados para otros propósitos, tanto de culto como prácticos. Poco a poco, la mirada estética iría institucionalizándose hasta fundar el museo, donde solo irían destinadas aquellas obras que desde el propio punto de vista museístico podían ser consagradas como arte. 


\section{FIGURA 1}

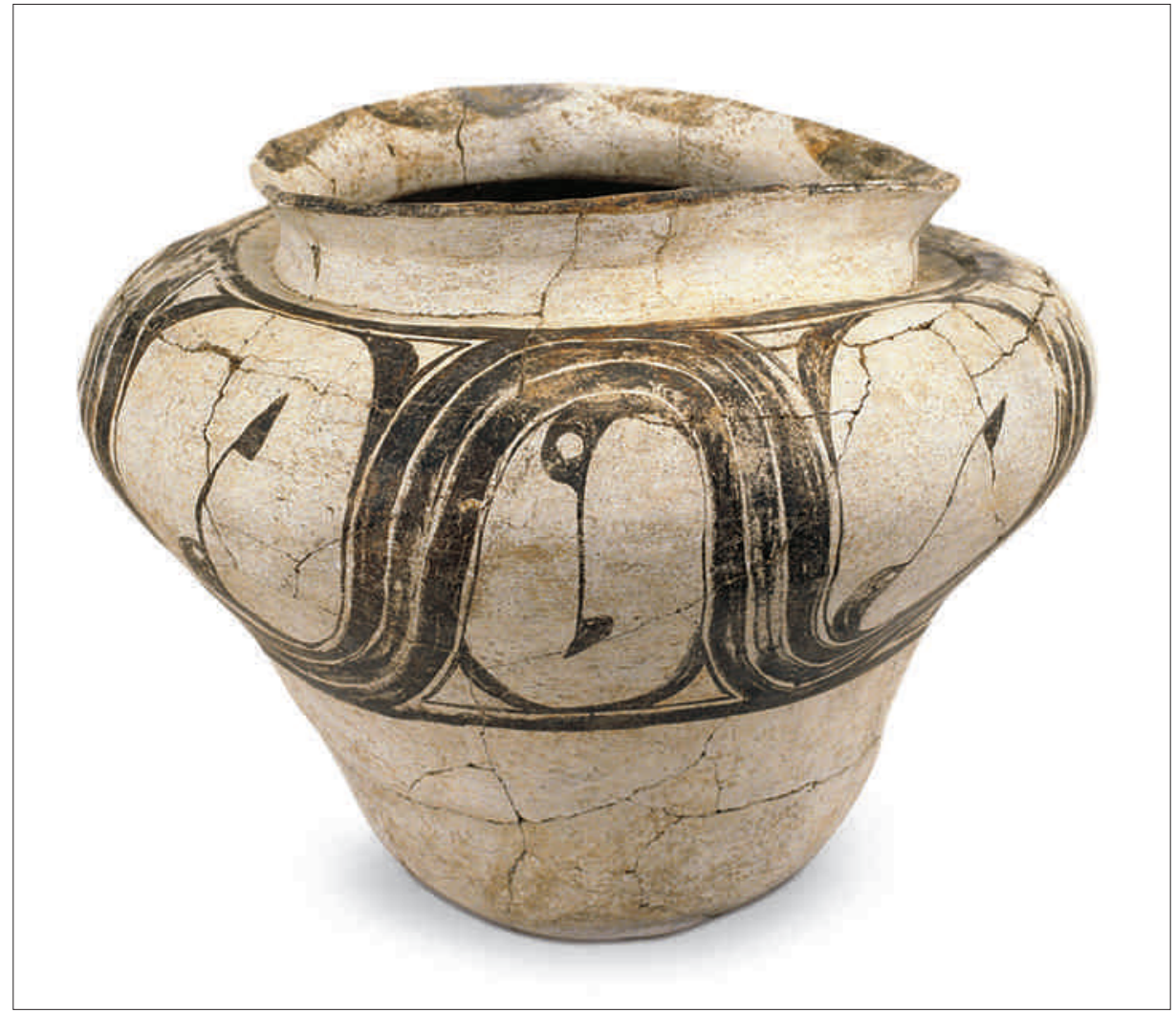

Vasija del estilo Camay. Serie Tocuyanoide: 300 a. C.-400 d. C., Estado Lara, Venezuela. Colección Reinhard Kistermann. Fotografía cortesía del coleccionista.

De esta manera, la distinción entre lo prehispánico y la producción de cultura material indígena actual y mestiza se ha ido haciendo cada vez más palpable, incluso entre la literatura histórico-artística latinoamericana. Los estudios de arte precolombino suelen darle una evidente predominancia al arte de culturas monumentales y grandes civilizaciones (maya, azteca, inca), con las que el hombre europeo se vio quizás más identificado; mientras que las culturas seminómadas o demográficamente más pequeñas y con menor cantidad de cultura material (como las culturas que habitaron y habitan en regiones que actualmente conforman Venezuela) despertaban por lo general un interés puramente científico o antropológico. De hecho, en los estudios de Alcina Franch (para dar un paradigmático ejemplo de la literatura histórico-artística de arte precolombino en español) no hay siquiera mención del arte prehispánico procedente de las regiones amazónicas y del Caribe.

Dentro del propio contexto venezolano el historiador y crítico de arte Alfredo Boulton hizo una distinción tajante entre la cerámica prehispánica y aquella posterior 
al período colonial $(17,24)$. Consideraba que la primera contenía un valor artístico, mientras que la segunda carecía de cualquier intención estética. No está de más recordar que tanto para Boulton como para muchos otros historiadores del arte, el valor artístico parecía ser incompatible con la productividad y la cotidianidad.

Colegimos por tanto que su concepto de arte solo abarcaba la esfera de lo sagrado y lo contemplativo, excluyendo del todo aquellos significados menos visibles - que escapan por lo general al entendimiento directo de lo que podría ver un ojo externo-, así como aquellos elementos funcionales y cotidianos que se alejaran aparentemente de los valores que para el ojo estético de tradición europea serían trascendentales. Entendemos que para estos autores el valor del arte no yacía solamente dentro de la obra en sí, sino que se fundamentaba también en la ya mencionada concepción de "pureza" o de "autenticidad" de la producción artística: dicha concepción sugería por tanto que si esta estaba mezclada con conceptualizaciones occidentales, no podía ser considerada como "arte" (autónomo), propiamente dicho.

Estas posturas podrían encontrar cierta correspondencia con algunas nociones sobre el arte elaboradas a partir del siglo xx, como el complejo concepto de "aura" acuñado por Walter Benjamin, para quien el arte mantenía una relación indisociable con el elemento sagrado y trascendental, insertándose necesariamente en el contexto ritual: Las obras artísticas más antiguas sabemos que surgieron al servicio de un ritual primero mágico, luego religioso. Es de decisiva importancia que el modo aurático de existencia de la obra de arte jamás se desligue de la función ritual. Con otras palabras: el valor único de la auténtica obra artística se funda en el ritual en el que tuvo su primer y original valor útil. Dicha fundamentación estará todo lo mediada que se quiera, pero incluso en las formas más profanas del servicio a la belleza resulta perceptible en cuanto ritual secularizado. Este servicio profano, que se formó en el Renacimiento para seguir vigente por tres siglos, ha permitido, al transcurrir ese plazo y a la primera conmoción grave que le alcanzara, reconocer con toda claridad tales fundamentos. Al irrumpir el primer medio de reproducción de veras revolucionario, a saber la fotografía (a un tiempo con el despunte del socialismo), el arte sintió la proximidad de la crisis (que después de otros cien años resulta innegable), y reaccionó con la teoría de "l'art pour l'art", esto es, con una teología del arte. De ella procedió ulteriormente ni más ni menos que una teología negativa en figura de la idea de un arte "puro" que rechaza no solo cualquier función social, sino además toda determinación por medio de un contenido objetual (4).

A partir de este párrafo puede colegirse que según Benjamin, antes de que existiera una noción autónoma del arte, este se vería intrínsecamente ligado con valores y significados trascendentales-religiosos. Sería a partir de la creación de una nueva noción de arte contextualizado a partir del Renacimiento cuando se generaría una visión secularizada de estos elementos ligados a las ideas de lo sagrado. El arte adquiere 
así algunas cualidades trascendentales asociadas tradicionalmente con la religión; y por tanto, lo prehispánico ha logrado obtener un valor artístico gracias, en parte, a las connotaciones religiosas y rituales que contienen las piezas de manera inherente (véase Holsbeke 319).

En cualquier caso, no puede faltar la relación prístina con lo trascendental, ya que esto es lo que aseguraría su valor como "auténtico". Emparentados con estas ideas, la autenticidad para historiadores como Boulton solo podía darse en aquellas piezas amerindias que se encontraran definitivamente alejadas de cualquier posible "contaminación" del contacto con la cultura europea y con cualquier funcionalidad y significado que no fuera ritual y sagrado.

A parte del valor intrínseco religioso, los motivos por los que se le atribuye sin mucho esfuerzo un valor artístico a las piezas prehispánicas están motivados, en parte, por ciertos ideales que fueron acarreándose desde el pensamiento hegeliano sobre un arte que va de la mano con el "espíritu del tiempo" (Pasztory 8), y cuyo propósito fundamental es el de trascender la forma hasta un estado atemporal, ideal-espiritual (Hegel 31-36). La historia (el transcurso tiempo) y sus supervivientes se convierten así en vestigios de lo sagrado; y la apropiación de objetos pertenecientes a culturas ancestrales - incluyendo al arte llamado "primitivo"-, que constituyen arcanos para la sociedad moderna occidental, se transforman en símbolos de la historia de la humanidad.

Como ha destacado Baudrillard, al ser apropiado por la mirada estetizante, el objeto renuncia a su utilidad para convertirse en un objeto abstraído de su funcionalidad y significación originales (121); es así que este adquiere un estatuto "subjetivo" y coleccionable. Ahora bien, el objeto arcano adquiere una connotación aún más especial: este obtiene de por sí un significado mítico (para el ojo estetizante) por el hecho de poseer una carga temporal. En palabras del pensador, "el objeto antiguo es, en sí, puramente mitológico dada su referencia al pasado" (104). Por consiguiente, aquellos objetos recubiertos por la pátina del tiempo o bien, que remiten a culturas que desde el imaginario occidental pertenecen al illus tempus (como aquellas sociedades "primitivas" e intocadas por la "modernidad"), podrán valorarse como artísticos. A esto se le añade el hecho de que, según Baudrillard, el coleccionismo siempre ha estado condicionado por la nostalgia del pasado y la obsesión por la autenticidad (107).

Este ideal coincide con el interés hacia lo "primitivo" y su inclusión dentro del campo artístico occidental por parte de los artistas de las Vanguardias europeas a inicios del siglo xx, emparentados aún, en algunos aspectos, con un pensamiento romántico. Fueron ellos quienes se sintieron atraídos por estos objetos, partiendo por vez primera de una valoración estética y no desde el interés antropológico o etnológico (véase Ocampo "La civilización”). Iniciaron, de este modo, una tradición que intentaba catalogar el arte no-occidental como un objeto estético capaz de dialogar con las prácticas artísticas desarrolladas en Europa. 
Ha sido en este contexto que en países latinoamericanos se ha elevado la cultura material prehispánica al pedestal del arte. Dicha valoración estética ha tenido su consecuente correspondencia con las variaciones acontecidas en el mercado: el arte prehispánico ha sido incluido en las redes de comercio del arte consagrado (en casas de subastas como Christie's y Sotheby’s), mientras que la artesanía suele tener precios relativamente bajos y fluye en circuitos comerciales populares (mercados de artesanías y tiendas de souvenirs).

En resumidas cuentas, la apreciación de la cultura material de los pueblos prehispánicos o pueblos alejados del mundo occidentalizado se ha visto frecuentemente teñida de una mirada nostálgica hacia una idea de lo "primitivo" que remite a culturas extintas o en vías de hacerlo, y de las cuales no nos quedan más que vestigios que algunas piezas arqueológicas o registros etnográficos. Al encontrarse estas prácticas impregnadas de una pátina histórica que remite a lo arcano, estas pueden responder con mayor facilidad a una categoría "aurática" que las eleve a la esfera del arte.

\section{La desacralización del presente o del mundo indígena mestizado con el mundo occidentalizado}

Los objetos pertenecientes a la cultura material del presente amerindio - aquel que irremediablemente se encuentra en un proceso de continuidad y cambio entre sus tradiciones y la influencia del mundo occidentalizado- no han tenido la misma suerte en el proceso de estetización que los objetos de culturas arcanas y prehispánicas. Así lo podemos observar en el ejemplo de la cestería ye'kuana del Amazonas venezolano (figura 2), la cual se convierte en un objeto de artesanía coleccionable, pero que en el fondo no llega a adquirir dentro de la cultura occidentalizada el mismo valor que podría tener una vasija precolombina. El problema es que, por lo general, el concepto de artesanía se encuentra disociado de todo valor estético autónomo, debido a su aparente "falta" de relación con lo sagrado, su inherente imbricación con el mundo práctico, cotidiano y comercial (el cual, por otro lado, también existe en el arte prehispánico) y su condición mestizada o híbrida con la tradición europea.

Por ello, el mundo indígena tradicional ha sido considerado actualmente como un universo cultural en peligro de extinción; con frecuencia se utiliza aún la palabra "aculturación" para describir este proceso de hibridación del mundo indígena con el occidentalizado, entendiendo con esta idea que se han perdido los valores propios y los fundamentos míticos que identificaban a sus antecesores prehispánicos. De este modo la cultura material producida por estas sociedades ha sido comercializada hoy en día desde un mercado más informal, destinado principalmente al turismo.

De aquí surge la pregunta: ¿por qué suele apreciarse más una cultura completamente apartada a la occidental (lejana, arcana) que una cultura mestiza y sincrética (y actual)? Se podría pensar que esto se debe al hecho de que la mayoría de los objetos 
FIGURA 2

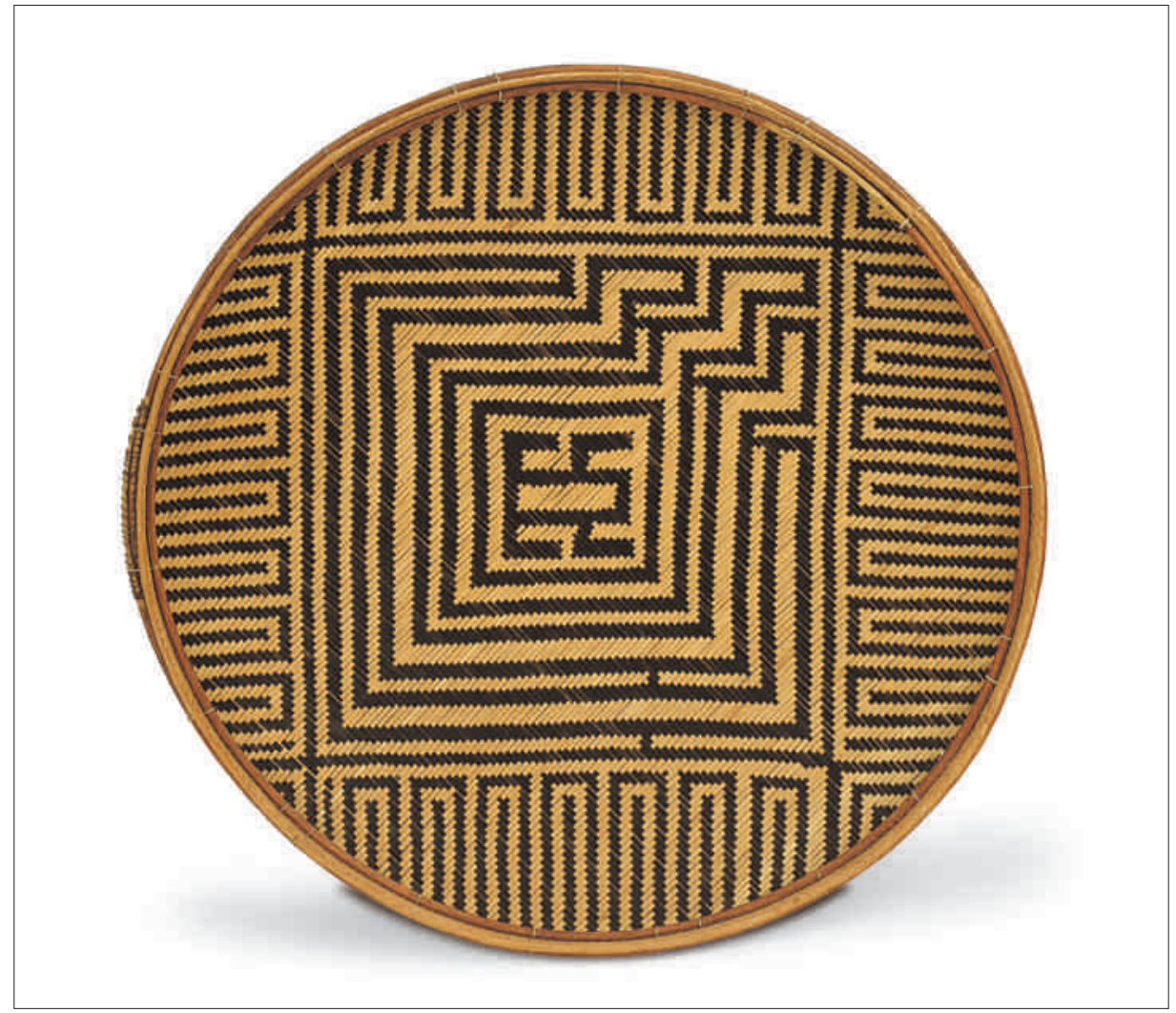

Cesta tipo wapa de la cultura ye’kuana, Estado Bolívar, Venezuela. Colección Reinhard Kistermann, Aquisgrán. Fotografía de la autora.

que pertenecen a dicho universo material contienen una funcionalidad práctica, o son realizados masivamente para un contexto comercial globalizado. Mas entonces tampoco se podría justificar la presencia del diseño "occidental” en las grandes instituciones del arte: un iPod o una cafetera puede encontrarse en un museo de arte contemporáneo (por ejemplo, en el MoMA de Nueva York); en cambio, la cesta podría hallarse con suerte en un museo de ciencias naturales o en un museo etnológico.

De hecho, la discusión en torno a la autonomía del arte tan encarecida para autores como Escobar ya ha sido superada en gran medida, pero solo si se trata de la tradición artística occidental. Ya con el inicio del Dadaísmo y Bauhaus puede comenzar a zanjarse la idea de una autonomía artística tal como la planteaba Kant. En la medida en que el arte se fue conceptualizando, politizando y convirtiendo en herramienta de movilización cultural y, a su vez, en la medida en que el arte y el diseño de objetos funcionales e industriales pertenecieran al mismo círculo de creadores, ha sido cada vez más difícil mantener una idea de arte autónomo. No obstante, Bourdieu reconoce 
una persistencia por parte de la intelectualidad occidental en revindicar aquel elemento "culto" del arte, entendido, por supuesto, según los propios parámetros eurocéntricos:

[...] cabe preguntarse si hay que considerar la revolución estética que se afirma en la teoría de la realidad superior del arte y del genio autónomo, como una simple ideología compensatoria suscitada por la amenaza que la sociedad industrial y la industrialización de la sociedad intelectual hacen pesar sobre la autonomía de la creación artística y sobre la singularidad irremplazable del hombre cautivado (246).

En todo caso, desde los mismos orígenes de las concepciones estéticas occidentales, el trabajo artesanal ha sido reducido de por sí a una esfera inferior que el arte, particularmente cuando esta artesanía ha provenido de individuos ajenos a esa intelectualidad cultural occidental.

Esta resistencia en valorar todo trabajo que no pertenezca a las esferas consagradas de la intelectualidad se halla también en las bases del pensamiento occidental: como podemos leer en El artesano de Richard Sennett, al ser herederos de ciertos preceptos nacidos bajo el influjo de los ideales platónicos y aristotélicos sobre la preferencia de la metafísica ante las labores físicas, el trabajo manual ha sido devaluado frecuentemente por la tradición occidental a un tipo de ocupación mundana que no requiere esfuerzo espiritual y quedaría por tanto excluido de la esfera de las artes (33). La preferencia por las profesiones intelectuales ante las manuales ya tiene lugar tanto en La República de Platón, así como en la en la Metafísica de Aristóteles, quien aseveraba que el artesano no sabía las razones por las cuales elaboraba sus objetos, al contrario de los oficios "mayores", como la arquitectura.

Además, sostenemos que la devaluación del producto artesanal está relacionada con la idea un tanto distorsionada que se intenta forzar sobre las culturas que generan estos objetos estéticos no-occidentales. En el momento en que las culturas llamadas "primitivas" o "exóticas" comenzaron a entrar en relación con las dinámicas culturales occidentales y se mestizaron con esta, perdieron aquel "aura" que les confería autenticidad y que las relacionaba con formas simbólicas primigenias. Las culturas amerindias actuales viven, según esta perspectiva, en un estado mestizado o híbrido debido a que han adoptado la idiosincrasia occidental, a pesar de seguir manteniendo algunos vestigios tradicionales. Como consecuencia de esto, la nueva condición del mundo amerindio ha vivenciado un proceso de desacralización, no solo en su cosmogonía, sino también en todo su universo material. Desde una sesgada perspectiva, al ser concebidos en parte para la venta al turista o a mercados occidentalizados, los objetos que una vez fueron rituales o que tuvieron un valor mítico, pasan ahora a ser — desde la perspectiva del consumidor occidental- objetos despojados de valor estético.

La problemática sobre la valoración de la artesanía indígena en la actualidad se emparenta también con los debates generados en torno al concepto de tourist art acuñado por Nelson Graburn. Este corresponde a aquel tipo de producción estética 
elaborada de manera masificada y que se adapta a los cánones de una cultura externa. Al contrario, Graburn distingue el tourist art de la artesanía, la cual según el autor es realizada con propósitos sociales propios y está destinada a las necesidades de la cultura que la crea, lo que la ayuda a mantener la identidad étnica y la estructura social a través de la perpetuación de la tradición.

Como hemos venido aseverando en anteriores trabajos, se hace difícil si no imposible determinar la calidad estética de un objeto según los propósitos para los cuales fueron creados, discriminando entre aquellos "tradicionales" y "auténticos", y los que son realizados con propósitos “comerciales". De hecho, la autenticidad de las piezas elaboradas por culturas lejanas y exóticas que cayeron en manos del coleccionista occidental debe ponerse siempre en duda. Numerosas contradicciones se presentan al intentar determinar, por ejemplo, la autenticidad de una máscara o atuendo ritual al especificar si esta ha sido "bailada" o utilizada. Desde los comienzos del coleccionismo de las artes "primitivas", las piezas recaudadas fueron frecuentemente réplicas de los objetos originales; hecho demostrado en numerosos ejemplos del siglo XVIII y XIX, donde los objetos adquiridos como especímenes etnológicos y obras de arte eran mandados a hacer por los viajeros europeos (Phillips y Steiner 10). Lo cierto es que la mayoría de los objetos rituales, tanto de las culturas africanas como de las amerindias, son desechados o destruidos tras haber sido usados; por lo que la mayoría de los objetos que llegaron a las colecciones y a los museos de arte fueron probablemente encargados por los extranjeros que viajaron a estas poblaciones. Damos por ello cuenta que numerosas piezas que hoy son consagradas en el mundo del arte como auténticas representaciones del imaginario votivo y mítico de diversas culturas no-occidentales fueron elaboradas, en muchas ocasiones, expresamente con fines económicos.

Continuando en un ámbito parecido, Graburn advierte que los objetos categorizados como "artesanales" han sido producidos por sociedades que tuvieron que modificar su propia cultura material como respuesta a la necesidad de adaptarse a sistemas políticos y económicos extranjeros. Es reseñable el hecho de que las modificaciones realizadas en la artesanía son motivadas, precisamente, por la búsqueda de satisfacer los gustos estéticos del consumidor occidental. El tourist art se distinguiría de la artesanía propiamente "tradicional" en el sentido de que ya no se realiza bajo un sistema simbólico y estético propio, sino que depende de los intereses de otra cultura. Pero lo cierto es que también este transmite en la mayoría de los casos las insignias de la identidad indígena y contiene aún elementos simbólicos propios de su tradición.

$\mathrm{Al}$ asumir esta condición de hibridismo cultural que se manifiesta a nivel global, podemos enfocar nuestro discurso hacia el debate en torno a la "apropiación", ya estudiada por James Young. Las fronteras que separan una cultura de otra se hacen cada vez más borrosas y es difícil definir cuándo una está en derecho de reivindicar su identidad respecto a otra. En nuestro caso de estudio pueden identificarse dos tipos de apropiación artística: por una parte, la sociedad occidental ha incorporado 
algunos objetos indígenas en su acervo cultural y comercial; por otra, las sociedades indígenas también se han homologado al mundo occidentalizado, incorporándose (en parte) al sistema económico y adoptando ciertos cánones estéticos. La recepción de estas apropiaciones ha sido sin embargo diferente: en el primer caso, el mundo occidental se apropió de las prácticas estéticas prehispánicas, insertándolas dentro del mundo artístico "elevado" o "culto". En cambio, en el segundo caso, la apropiación de rasgos occidentales por la cultura indígena ha sido parte del motivo por el cual sus prácticas actuales han perdido su valor estético.

Un matiz de lectura importante sobre este tema puede encontrarse en el texto de Sagrario Berti, Arte/sanía venezolana, ¿por función, elaboración, o uso?, en el que evidencia cómo las culturas indígenas que viven en el territorio venezolano han tomado prestados algunos modelos culturales del mundo "occidentalizado". Mas este último también se ha apropiado en cierta medida de las prácticas y la cultura material indígenas, incorporándola como un elemento folklórico y, por lo tanto, como insignia de una identidad y una cultura nacional. En su ensayo, Berti ha planteado la problemática que surgió a partir de la valoración atribuida a la artesanía en Venezuela, e hizo patente el hecho de que las piezas artesanales son aisladas y despojadas de cualquier referencia a la cotidianidad cuando se les intenta trasladar a un plano más estético (2). No obstante, la autora ha propuesto un replanteamiento de la valoración de la artesanía, según el cual debe apreciarse la obra artesanal en su contexto, tanto inicial (el sujeto que la crea) como posterior, cuando es utilizada como objeto estético o funcional. De este modo, las relaciones que establecemos de por sí con los objetos son siempre simbólicas. En otras palabras, el objeto va cambiando de significado a medida en que se le atribuye una función o una ubicación distinta (4).

La valoración estética del objeto cambia drásticamente según el uso que se le dé, a pesar de que la forma continúe siendo relativamente la misma. Un ejemplo paradigmático son las cestas indígenas utilizadas para el procesamiento de la yuca (mandioca). Dentro de su contexto funcional originario, estas contienen un claro valor simbólico, debido en parte a que son responsables de exprimir el veneno que se encuentra en la yuca amarga y de proveer el alimento sustancial de la dieta amazónica. Mas, al ser producidas para la venta al turista, estas adquieren otro significado que, para el ojo estético occidental, suele carecer de aquel valor simbólico relacionado con su funcionalidad originaria.

Con estas ideas se propone por tanto una nueva visión sobre cómo interpretar la artesanía, tomando en cuenta los diversos usos que se le puede dar según el contexto cultural. Así, se pueden interpretar los nuevos usos otorgados a la artesanía a partir de una progresiva homogenización del mercado a nivel mundial. Se hace comprensible que, para competir en un mercado de arte o artesanía globalizado, así como para satisfacer mejor sus propias necesidades, las culturas indígenas se han adaptado a las nuevas exigencias y contingencias del mundo no-indígena, "apropiándose” — por así decir - de las nuevas tecnologías y preferencias estéticas. 
De este modo, el objeto artesanal "tradicional" es utilizado hoy en día en el espacio criollo sobre todo como decoración, independientemente si su propósito original haya sido funcional o religioso/espiritual. Sin embargo, Berti ha preferido ver estos cambios en la funcionalidad y en la valoración de los objetos artesanales como una re-contextualización del objeto, más que como una devaluación de su significado: "recontextualizar el objeto artesanal supone una manera de re-socializarlo" (33). De esta manera, la valoración de la obra no se encuentra dentro del objeto en sí, sino también en el entorno, el uso y la significación que se le da al objeto después de ser creado.

Siguiendo esta línea de pensamiento, encontramos cómo Emanuele Amodio ya había advertido que en la medida en que el mercado de la artesanía indígena actual es manejado por los criollos (la sociedad occidentalizada), los cánones estéticos estarían controlados por estos. Ello implica que las culturas indígenas han ido adaptándose a la demanda del mercado y, si es necesario, modificar sus tradiciones para poder sobrevivir en la red comercial global. Allegados, pues, a las perspectivas que ofreció Amodio sobre la actual situación de la artesanía indígena, preferimos no hacer una división dicotómica entre una artesanía tradicional y otra que correspondería a un tourist art.

Debe tenerse en cuenta que en el mundo indígena los cambios históricos - políticos, económicos, tecnológicos, étnicos, etc.- van actualizándose en los mitos de creación amerindios, devolviéndole a la cultura material una nueva justificación y simbolización de su vida actual. Es así que las nuevas formas de hacer artesanía también pertenecen a las estructuras "tradicionales", puesto que están en un constante proceso de adaptación. Como ha subrayado Amodio, "no hay objetos tradicionales y objetos que no lo son, sino productos culturales que realizan su función, sea económica o simbólica, y cuando no la realizan, cambian o desaparecen" (11).

En resumidas cuentas, y tal como lo ha expresado Jean-Loup Amselle, las sociedades de tradición oral han demostrado ser incluso menos estáticas y más abiertas al cambio y a la maleabilidad que las sociedades con escritura, las cuales tienden a fijar más la tradición en estructuras rígidas (Logiques 56). La creación de imágenes, formas simbólicas y objetos varios, que retratan y materializan la cosmogonía y las dinámicas culturales de estas sociedades se establece en un constante vaivén que oscila entre la conservación de una tradición ancestral y la aplicación de nuevas técnicas e ideologías innovadoras.

\section{La maleabilidad de los mitos amerindios y su cultura material}

Sabemos entonces que el proceso de valoración estética de la cultura material amerindia también ha pasado por esta distinción entre aquello que es "auténtico" y que no - es decir, entre los objetos elaborados dentro de las propias categorías míticas y cosmogónicas, y aquellos objetos "desacralizados" y desasociados del contexto cultural original-. No obstante, el ojo estético occidental parece obviar 
en muchas ocasiones la capacidad de renovación de los discursos míticos, los cuales van añadiendo los cambios culturales y, consecuentemente, las formas de concebir la cultura material.

En primer lugar, los procesos de mestizaje entre las culturas amerindias con el mundo occidentalizado son complejos. Se debe tener en cuenta que el grado de mixtura con la cultura criolla varía según cada grupo étnico, e incluso de un poblado a otro. Estas variables dependen de la ubicación geográfica y de la accesibilidad de cada población (si están más o menos apartadas de centros urbanos criollos), sin olvidarnos del tipo de contacto que han establecido con el mundo occidental. Asimismo, la mutabilidad está sujeta al tiempo que cada poblado tiene relacionándose con este, al nexo comercial y a la influencia que han podido ejercer las misiones religiosas, ${ }^{2}$ las incursiones modernizadoras gubernamentales y el turismo. Podemos hallar, en este sentido, un amplio abanico de matices que incluyen sociedades que se han mantenido casi al margen de todo contacto con el mundo occidental, así como aquellas cuya relación con este es prácticamente indisoluble.

En segundo lugar, tal como lo ha elucidado Ocampo, la cultura material amerindia está concebida de manera tal que encontramos imbricadas múltiples funciones y significados, tanto sagrados como funcionales. Por lo tanto, objetos que desde la perspectiva occidental podrían parecer deslindados de cualquier significado, como una cesta de carga o una canoa, son para el mundo amerindio objetos sagrados, puesto que todos los conocimientos que posee el hombre para sobrevivir en el mundo han sido enseñados por entidades espirituales y están contenidos en los mitos. Cualquier uso de tecnología tradicional en este mundo es una forma de actualizar y revivir los mitos y las enseñanzas de los antepasados.

En definitiva, el objeto estético amerindio, tanto prehispánico como contemporáneo, sirve como intercesor entre el mundo material con el mundo mítico; incluso en aquellos casos en los que el objeto haya sido concebido en una sociedad híbrida y que ha adoptado diversas tradiciones, la amerindia, la europea, la africana, etc. Todos estos objetos generan conocimiento y a la vez son funcionales. La particularidad de estos se fundamenta en la "imbricación" entre el elemento simbólico y el elemento práctico se encuentran replegados el uno en el otro.

Así lo vemos en el caso de estudio venezolano, donde sociedades indígenas como la ye'kuana - pertenecientes a la familia lingüística de habla Caribe-comenzaron a entrar en mayor contacto con el mundo "criollo" apenas a partir de mediados del siglo xx. Esto representa un particular interés ya que es posible observar cómo a lo largo de aproximadamente medio siglo la forma de vida de los ye'kuana ha cambiado drásticamente, así como la visión y valoración de su cultura desde la perspectiva occidentalizada. Sin embargo, sociedades como esta poseen una compleja cosmovisión

2 Véase al respecto, por ejemplo, Caputo Jaffé. 
fundamentada en los mitos, que determina todos los quehaceres del hombre en sociedad y en su interacción con la naturaleza. Pertenece por tanto a aquellas culturas indígenas englobadas dentro de las formas de pensamiento amazónico, estudiadas extensamente desde la antropología por autores como Lévi-Strauss, Descola y Viveiros de Castro.

Lévi-Strauss definió la manera de obrar en el mundo de las culturas amazónicas con el concepto de bricolaje, acuñado en su Pensamiento salvaje. Con este, el autor abrió paso a una interpretación de las prácticas amerindias actuales que se encuentran en una relación indisoluble con otros tipos de conocimiento y con el mito. La noción de bricolage define una forma arbitraria de pensamiento en el que encontramos entreveradas las claves para comprender la naturaleza, la creación de los mitos y de los objetos utilitarios (Lévi-Strauss 47-48). La idea de bricoleur responde al artífice y pensador de la cultura material amerindia, quien toma elementos dispersos que encuentra en la naturaleza, así como retazos del discurso mítico que le son útiles para elaborar un nuevo tipo de conocimiento, ofreciendo así una visión actualizada del mundo. De acuerdo con esto, los elementos traídos de la naturaleza que vemos plasmados en las formas visuales siempre conllevan un proceso de abstracción, en el que se ha filtrado la presencia mítica. Además, los objetos realizados para el uso propio por los pueblos indígenas de América — como las cestas ye'kuana— aún suelen elaborarse respetando las reglas ritualizadas, asociadas a los mitos de origen, las cuales aseguran una función exitosa y eficiente del objeto en la sociedad.

Lo que no suele tomarse suficientemente en cuenta es que incluso los nuevos objetos añadidos al universo material indígena producidos para la exclusiva venta al turista — algunas cestas o bancos de madera - también han sido incluidos en las narraciones míticas. Para los ye’kuana todos los objetos producidos por ellos fueron aprendidos de los héroes míticos en tiempos primordiales. Su ciclo de creación, llamado el Watunna, contiene todos los conocimientos culturales del hombre, incluida la elaboración de todo tipo de objetos de uso cotidiano y ritual. En cuanto mitos, su esencia consiste en ser perpetuamente moldeables al tiempo, al uso, a la necesidad de adaptarse a cada contingencia histórica. En la medida en que son conocimientos que se traspasan a través de la oralidad y la memoria individual y colectiva, cada vez que son contados adquieren nuevos matices, se les añaden diversas informaciones. Así, de la misma manera en que los mitos dan razón de ser y forma a los objetos, las nuevas contingencias históricas y los objetos que van introduciéndose en la cultura también van reconfigurando las narrativas míticas.

Hemos podido corroborar en este sentido que los ye'kuana han incorporado nuevas versiones de mitos que dan origen a la cestería realizada por las mujeres para la venta al turismo, denominadas wïwas ${ }^{3}$ (figura 3). Relatan las ancianas hoy en día

3 Las wïwas eran originalmente las cestas de carga y almacenamiento elaboradas tanto por hombres como mujeres. Hoy en día estas cestas han sido modificadas (son más pequeñas, se hacen en diversas formas y se utilizan diversos patrones y fibras de colores) para la venta al turismo. Las cestas tradicionales elaboradas para el procesamiento de la yuca son trabajo exclusivo de los hombres. 
FIGURA 3

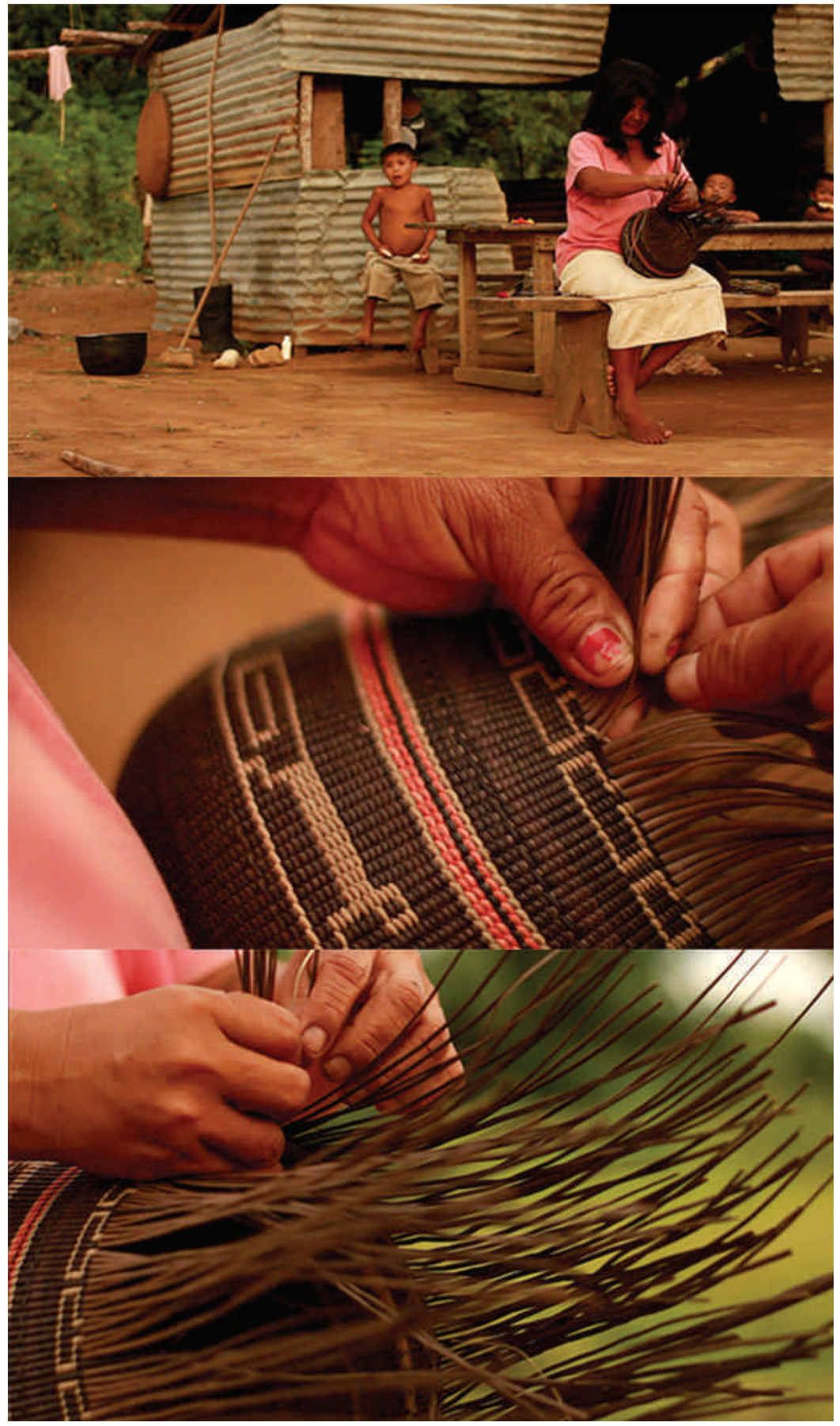

La artesana Susana Montiel teje una wïwa, cesta destinada al comercio turístico. Comunidad de Surapire, Estado Bolívar, Venezuela, 2011. Fotografía tomada por la autora. 
que tanto las cestas tradicionales para uso propio como aquellas para la venta a los turistas se encontraban dentro del saco del gran mono mítico Iarakaru. ${ }^{4}$ Dice el mito que los hombres mantuvieron una larga lucha contra los Warashidi, monos gigantes que oprimían y devoraban a las personas. Cuando finalmente los hombres lograron vencer a los monos caníbales, robaron un bolso sagrado a su jefe llamado Iarakaru, encontrando en su interior todos los posibles tipos de cestas y patrones visuales con los cuales son decorados; incluso los productos "novedosos" o "híbridos", es decir, las cestas que fueron creadas para la venta al turismo, lo que significa que estas han pasado a formar parte de la identidad cultural y están contenidas en el origen mítico de estas sociedades.

Destaca por lo tanto la versatilidad y capacidad de cambio de los mitos, los cuales pueden adaptarse a las diversas situaciones y contingencias históricas ya que van incluyendo los nuevos episodios históricos de su cultura. Pero sobre todo, destaca el hecho de que no existe ninguna función o ningún objeto menos valioso a nivel cultural y mítico para los ye'kuana, siempre y cuando sean creados por ellos y formen parte del sustento de la sociedad. Como pudo señalarlo Guss, en idioma ye'kuana todos estos objetos realizados dentro de su universo cultural se engloban dentro del concepto tidiuma (Guss 95).

Se hace de este modo necesaria una apertura de las fronteras conceptuales al tratar con este tipo de sociedades, sumamente permeables al cambio; debido en parte a su naturaleza oral así como al fundamento mítico de su organización social y de la perpetuación de la memoria. Pero sobre todo, debido a la condición imbricada en la que está conexionada la cultura material. Todo objeto tiene su lugar en los mitos y, por lo tanto, sus formas de representación remiten a un significado trascendental. En concordancia con lo expuesto por Severi, tratamos con tradiciones "donde el ejercicio gráfico complementa la función de la palabra” (20). Así, los mitos sirven como guías en la elaboración de la cultura material; y, a la vez, los objetos, sus decoraciones y estilos sirven como recuerdo y reactualización de los mitos en el día a día.

\section{Conclusiones: un acercamiento imposible hacia lo ajeno}

Pese a los nuevos aportes antropológicos e históricos que han ofrecido algunas lecturas poscoloniales con la intención de romper con ciertos prejuicios sobre el concepto de tradición, la entrada de la cultura material amerindia en el mundo del arte y, en general, la cultura occidental, continúa siendo un proceso difícil. Pero entendemos que las razones que conducen a que el arte prehispánico o arte de culturas arcanas

4 Esta información se obtuvo en diversos trabajos en terreno en comunidades ye'kuana a lo largo del río Caura, Estado Bolívar, así como del río Cunucunuma, Estado Amazonas, en Venezuela. Algunas entrevistas se encuentran transcritas en la tesis doctoral de la autora (Caputo Jaffé, Continuidad Anexos). 
sea considerado por lo común como "arte", mientras que el arte indígena actual y mestizado es considerado como mera "artesanía” — carente de significado y valor trascendental一, tiene que ver con estas nociones rígidas de tradición y de cultura, así como con ciertas posturas teñidas de una peligrosa nostalgia o anhelo de encontrar un mundo aún exótico y "primigenio" en estas sociedades.

Contrarios a esta perspectiva, hemos podido darnos cuenta de que la tradición no es un elemento que se puede fijar en formas estáticas: a partir de los mitos de creación de las sociedades indígenas comprobamos que la tradición va modificándose constantemente con el cambio del tiempo y va incluyendo momentos históricos trascendentales en los relatos fundacionales. Es precisamente la naturaleza moldeable y metamórfica de las tradiciones amerindias - y por lo tanto de sus mitos y de sus fundaciones cosmogónicas - lo que las convierte en culturas en constante devenir y en perpetuo cambio, sin que esto signifique que se pierdan todos los rasgos autóctonos.

A pesar de ello, tenemos en cuenta que el choque cultural con Occidente produjo en estas culturas cambios muy drásticos en comparación con el tipo de intercambio y mestizaje interregional que estas pudieran haber tenido con otras sociedades amerindias. Asimismo, tampoco pretendemos obviar el hecho de que el proceso de desacralización haya afectado íntimamente las estructuras sociales de estos pueblos y, por tanto, también la manera de concebir simbólicamente su mundo.

Sin embargo, en muchos casos se tiende a hablar de "aculturación" cuando en realidad estamos enfrentándonos a nuevos modos de adaptación y de pervivencia. Así, algunos de los objetos que se realizan hoy en día en las culturas indígenas en Venezuela han pasado a formar parte de un nuevo sistema comercial, bajo nuevos criterios de valoración occidentales. Salvo pocas excepciones, no podemos concebir prácticamente ninguno de estos grupos indígenas como completamente aislados o "autóctonos", ya que el proceso de mestizaje y las influencias recíprocas que han tenido estas comunidades con la cultura occidental moderna forman ahora parte sustancial de su propia cultura. Los objetos como las cestas, las telas y las tallas de madera contienen por ello una complejidad de significados mucho mayores a la que usualmente solemos atribuirles; y en los procesos de estetización por los que pasa la cultura material indígena no se toma generalmente en cuenta el valor intrínseco que estos tienen para la cultura que les da origen.

Así, al arrimo de las teorías aportadas por Mikel Dufrenne, la experiencia estética occidental parte aquí únicamente desde el espectador (en este caso, las instituciones de arte occidentales) excluyendo la perspectiva del propio artista (o cultura, en nuestro caso). Dicho de otro modo, la consagración de la obra como objeto estético/obra de arte, se encuentra aquí en manos del espectador (19). Entra aquí en juego la diferencia entre el objeto estético y la obra de arte concebida como tal: “[...] la obra de arte no agota todo el campo de los objetos estéticos; no define más que un sector privilegiado, desde luego, no restringido" (23). 
El objeto estético amerindio conoce por tanto diversos procesos de estetización según el grado de identificación con este y con la búsqueda que se tiene en el arte desde Occidente. Resulta en este sentido aclaratorio que aquellos objetos vistos como desacralizados no sean considerados como "arte", sino rebajados a una categoría de "artesanía", por el hecho de no mostrar explícitamente su relación con las nociones que desde Occidente se buscan encontrar en estas culturas - como nociones referidas a lo arcano, lo sagrado, el illus tempus, etcétera-. Por otro lado, esta falta de identificación con el objeto híbrido no toma en cuenta las nociones internas que tiene cada cultura de su propia tradición, ni tampoco la medida en que los elementos simbólicos, míticos y sagrados siguen prevaleciendo, aunque bajo nuevas formas, más sutiles, más hibridadas. Es así que el proceso de estetización de la cultura material amerindia responde estrictamente a unos ideales del arte que se tienen en Occidente, sin conocer las causas que mueven los procesos creativos de las culturas que se apropian.

El debate sobre la posible "artisticidad" de las prácticas estéticas no-occidentales comienza a exigir un replanteamiento de las concepciones internas del arte que tiene Occidente, que Descola ha reformulado como una "antropología de la figuración o de la puesta en imagen" (2). No es sorprendente que hasta el momento este tipo de prácticas haya sido objeto de estudio principalmente de la disciplina antropológica, la cual le da un especial valor al contexto en que estos objetos fueron realizados y a determinar los significados que tienen para sus creadores.

Mas no podemos dejar de sentir la necesidad de comenzar a repensar estos objetos también desde otras disciplinas que no sean exclusivamente antropológicas; entre ellas, la historia del arte y la estética. De hecho, no es nuevo que desde la perspectiva estética occidental nos hayamos apropiado de objetos que no fueron creados con el propósito del ser artístico: el arte de la Grecia arcaica o el arte medieval - para dar tan solo un par de ejemplos- no fueron creados bajo el concepto que se entiende hoy en día de arte. De esta manera, si hemos de dialogar con parte de la literatura que ha tratado este tema desde el campo latinoamericano, como Ticio Escobar, podemos concluir que la idea de autonomía artística que preocupa tanto al autor, entendida como aquel elemento determinante que impide una valoración estética plena al arte que no circule dentro de contextos estrictamente occidentales, no es aplicable a este campo. Aunque, dicho sea de paso, esta idea de autonomía ha tenido validez únicamente por un muy corto periodo de tiempo (desde el siglo XVIII hasta inicios del $\mathrm{xx}$ ), incluso dentro del contexto occidental. Es así que las prácticas artísticas en Latinoamérica pueden significar un foco importante para un replanteamiento y actualización de la apreciación y las concepciones artísticas en general, en la medida en que son constantes las confluencias entre lo "académico", "occidental" y lo "popular", “indígena” o no-occidental.

Sostenemos, en todo caso, que las categorías occidentales de arte no han tomado suficientemente en cuenta la valoración o los significados que las propias culturas indígenas suelen darle a su producción de cultura material. Estas categorías respon- 
den en cambio a las problemáticas en torno a lo "ajeno" o "lo otro" elaboradas desde Occidente. Tal como podemos pensar a partir de la lectura de Bernhard Waldenfels, lo ajeno suele ser visto con tintes estetizantes siempre y cuando escape de cualquier posible característica que haga referencia a nuestra propia identidad. Sin embargo, la experiencia de lo ajeno solo se da cuando es posible verificar lo que originalmente era inverificable (2). En otras palabras, podemos percatarnos únicamente de lo ajeno cuando este se encuentra irremediablemente en una situación de cercanía o imbricación que, paradójicamente, hace que ya no sea ajeno. Por ello, una vez teñido de nuestras propias influencias, este pasa a convertirse en un resultado contaminado y desidealizado o desacralizado.

Estas ideas se relacionan estrechamente con el concepto de etnocentrismo que condiciona la manera en que cada universo cultural se mira a sí mismo y su relación con otras culturas. Lo ajeno se convierte para la sociedad etnocéntrica en una suerte de Doppelgänger que, por lo general, refleja más sobre la propia cultura que está mirando que sobre aquella que es mirada. Esto conforma un problema evidente entre la cultura criolla venezolana y las poblaciones amerindias; disipadas y entremezcladas hasta un punto tal, que la frontera entre lo uno y lo otro es a veces imposible de discernir. Así, el mundo amerindio oscila entre la reivindicación de una propia identidad y la necesidad de adaptación a la sociedad criolla que impone nuevas dinámicas culturales, políticas y económicas. En dicho vaivén incesante, la identidad indígena es reconfirmada y negada a la vez.

Dicha indeterminación es lo que en gran medida hace imposible reconocer desde la perspectiva estética actual una "autenticidad" en su producción de cultura material; noción que, como hemos podido entreverar, ha sido hasta ahora una condición indispensable para establecer una valoración estética sobre un objeto o evento. Consecuentemente, el proceso de inclusión dentro de las categorías estéticas se hace sumamente difícil a la hora de juzgar el mundo material amerindio del presente, mientras que no es este el caso de la cultura material prehispánica, cuya "autenticidad" se reconfirma en el hecho de no demostrar "contaminaciones" occidentales. Por otra parte, al ojo estético occidental le es indiferente si esta cultura material está conformada por un compuesto híbrido de diversas culturas (el arte prehispánico está conformado por diversos estilos que se mestizaron con otros): lo importante es que no esté mezclada con las propias tradiciones culturales (occidentales). Teniendo en cuenta estos factores, la perspectiva estética se convierte, en efecto, en un campo un tanto escabroso al enfrentarse a sociedades que viven a caballo entre la independencia y la aceptación de los preceptos comerciales y los gustos occidentales.

En definitiva, hemos podido verificar por un lado la medida en que la aplicación de la historiografía del arte al estudio de la cultura visual de sociedades no-occidentales -que, por tanto, no poseen un concepto de arte en sí- arroja luz sobre el devenir histórico y cultural de estas a través de la imagen. Mediante las metodologías procedentes de la historiografía del arte y de la estética, pueden medirse por tanto las 
relaciones entre el hombre y el mundo sensible, así como la morfología de su cultura material. Visto además desde una perspectiva diacrónica y comparativa, estas morfologías reflejan, a su vez, los cambios en las concepciones de mundo, las formas de credo, las dinámicas sociales, etcétera.

Además, en cuanto objetos capaces de generar una experiencia estética, estos pueden entrar, por lo tanto, dentro del territorio artístico. Una vez dispuestos bajo esta lupa, en un contexto de arte propiamente occidental, observamos cómo estos objetos son colocados en distintas categorías (arte, artesanía, tourist art, etc.) según las valoraciones vigentes y los cánones artísticos que prevalezcan en cada época. La interpretación de estos objetos constituye por ello también un aporte para la comprensión de los propios preceptos estéticos que se tienen desde la cultura occidental. Mirar hacia fuera, en este sentido, resulta provechoso, no solo para entender lo que no nos pertenece, lo que nos es ajeno, sino para comprender nuestra propia percepción del mundo.

En resumidas cuentas, podemos ver que tanto en el arte contemporáneo - de corrientes más académicas y occidentalizadas - como en la apreciación de las artes procedentes de tradiciones indígenas, folklóricas o populares, se hace cada vez más necesario conocer el contexto de la obra, su fenomenología y trayectoria particular de los realizadores para poder valorarla realmente. El arte de culturas ajenas a la propia siempre ha exigido un conocimiento aún más profundo, e incluso antropológico, sobre la cultura en cuestión para poder apreciarlo realmente. Se hace necesaria, por tanto, una apertura cada vez mayor de nuestro campo conceptual hacia el reconocimiento de otras perspectivas y visiones de mundo. No basta, evidentemente, la visión de "arte" que se tenía durante el nacimiento de la estética occidental (que era naturalmente etnocéntrica, así como lo son en un principio la mayoría de las culturas): lo cierto es que, en un contexto en el que coexisten distintas perspectivas y visiones de mundo - como en Latinoamérica-, deberíamos ya haber llegado al momento en que seamos capaces de conocer y reconocer las complejas realidades que nos rodean.

\section{Referencias}

Alcina, José. Arte Precolombino. Madrid, Akal, 1990.

Amodio, Emanuele. La artesanía indígena en Venezuela, Caracas, Dirección Nacional de Artesanías y Arte Popular/Consejo Nacional de la Cultura, 1997.

Amselle, Jean-Loup. Logiques métisses. Anthropologie de l'identité en Afrique et ailleurs. París, Payot, 1999.

"Primitivism and Post-colonialism and the Arts". MLN, vol. 118, n 4, 2003, pp. 974-998. Aristóteles. Metafísica. Madrid, Gredos, 1990.

Baudrillard, Jean. Le système des objets. París, Gallimard, 1968.

Baumgarten, Alexander. G. L'Estetica. Palermo, Aesthetica Edizioni, 2000. 
Benjamin, Walter. Discursos interrumpidos I. Buenos Aires, Taurus, 1989.

Berti, Sagrario. Artesanía: Otra visión. Caracas, Fundación Empresas Polar, Casa Alejo Zuloaga, 2006.

Boulton, Alfredo. El Arte en la cerámica aborigen de Venezuela. Caracas, Alfredo Boulton, 1978.

Bourdieu, Pierre. "Campo intelectual y proyecto creador". Textos de teorías y crítica literarias (del formalismo a los estudios postcoloniales). Coord. Nara Araújo y Teresa Delgado. Madrid, Anthropos, 2010.

Caputo Jaffé, Alessandra. [b]Continuidad y cambio en el arte indígena en Venezuela. De la estetización de lo sagrado a la desacralización del mundo amerindio. Tesis para optar al grado de doctorado, Universidad Pompeu Fabra, 2014.

-—. [a] “Entretejidos ye’kuana: oralidad, mito, artesanía”. Antípoda. Revista de Antropología y Arqueología, no 31, 2018, pp. 109-130.

Danto, Arthur. Artifact and Art: African Art in Anthropology Collections. Nueva York, Center for African Arts, 1989.

Delgado, Lelia. Seis ensayos sobre estética prehispánica en Venezuela. Caracas, Biblioteca de la Academia Nacional de la Historia, 1989.

Descola, Philippe. "L'Envers du visible: ontologie et iconologie". Histoire de lart et anthropologie. París, Musée du Quai Branly/INHA, 2009, s. p. Visitado 10 de dic 2018.

Dufrenne, Mikel. Fenomenología de la experiencia estética, vol. 1: El objeto estético. Valencia, Fernando Torres, 1982.

Escobar, Ticio. El mito del arte y el mito del pueblo. Cuestiones sobre arte popular. Santiago, Metales Pesados, 2008.

García Canclini, Néstor. Culturas híbridas: Estrategias para entrar y salir de la modernidad. Barcelona, Paidós, 2001.

Goldwater, Robert. Primitivism in Modern Art. Cambridge, Harvard University Press, 1986.

Graburn, Nelson. Ethnic and Tourist Arts: Cultural expressions from the Fourth World. California, University of California Press, 1976.

Guss, David. Tejer y cantar. Caracas, Monte Ávila, 1994.

Hegel, G. W. F. Estética, tomo I. Barcelona, Alta Fulla, 1988.

Holsbeke, Mireille. The Object as Mediator. On the Transcendental Meaning of Art in Traditional Cultures. Antwerp, Etnografisch Museum Antwerp, 1996.

Hussak van Velthem, Lucia. "O objeto etnográfico é irredutível? Pistas sobre novos sentidos e análises". Boletim do Museu Paraense Emílio Goeldi. Ciências Humanas, $\mathrm{n}^{\circ} 1$ (7), 2012, pp. 51-66.

Lévi-Strauss, Claude. El Pensamiento Salvaje. México, Fondo de Cultura Económica, 2006.

Ocampo, Estela. Apolo y la máscara. La estética occidental frente a las prácticas estéticas de otras culturas. Barcelona, Icaria, 1985. 
- - "La civilización y lo salvaje". Nueva Revista, no 80 (marzo-abril), 2002, s. p.

Pasztory, Esther. Thinking with Things: Toward a New Vision of Art. Austin, University of Texas Press, 2005.

Phillips, Ruth y Christopher Steiner. "Art, Authenticity, and the Baggage of Cultural Encounter". Unpacking Culture: Art and Commodity in Colonial and Postcolonial Worlds. Berkeley, University of California Press, 1999, pp. 3-19.

Platón. La República o el Estado. Madrid, Gredos, 1993.

Rubin, William, editor. Primitivism in 20th Century Art. Nueva York, MoMA, 1984.

Sennett, Richard. El Artesano. Barcelona, Anagrama, 2009.

Severi, Carlo. "L'univers des arts de la mémoire. Anthropologie d'un artefact mental". Annales HSS, no 2, (mars-avril), 2009, pp. 463-493.

Viveiros de Castro, Eduardo. A Inconstância da alma selvagem, São Paulo, Cosac \& Naify, 2002.

Waldenfels, Bernhard. "Respuesta a lo ajeno. Sobre la relación entre la cultura propia y la cultura ajena”. Revista de Filosofía Universidad de Costa Rica, n 71, vol. xxx, 1992, pp. 1-6.

Young, James O. Cultural Appropriation and the Arts. Oxford, Blackwell Publishing, 2008.

Enviado: 23 octubre 2017

Aceptado: 29 octubre 2018 